\title{
Pecan Scab Severity-Effects of Assessment Methods
}

Clive H. Bock and Bruce W. Wood, United States Department of Agriculture-Agricultural Research Service (USDA-ARS)Southeastern Fruit and Tree Nut Research Laboratory, Byron, GA 31008; and Tim R. Gottwald, USDA-ARS-United States Horticultural Research Laboratory, Ft. Pierce, FL 34945

\begin{abstract}
Bock, C. H., Wood, B. W., and Gottwald, T. R. 2013. Pecan scab severity—Effects of assessment methods. Plant Dis. 97:675-684.

Pecan scab is caused by the fungus Fusicladium effusum, and is the most destructive disease of pecan in the United States. Accurate and reliable disease assessments are needed to ensure that data provide a measure of actual disease intensity. The Horsfall-Barratt (H-B) category scale and its derivatives are commonly used to assess disease. Estimates using the H-B scale were compared with nearest percent estimate (NPEs) for rating disease severity of pecan scab on valves of fruit. Both inexperienced and experienced raters were included in the experiment. Lin's concordance correlation showed that agreement using NPEs was variable $\left(\rho_{c}=0.57\right.$ to 0.96$)$, whereas estimates of disease severity using the H-B scale had similar agreement among most raters $\left(\rho_{c}=0.59\right.$ to 0.98$)$. Converted values of NPEs to the H-B midpoints (NPEH-B) also provided a similar range $\left(\rho_{c}=0.61\right.$ to 0.96$)$.

using any of the three methods. Bootstrap analysis indicated that, among experienced raters, precision (r) and agreement $\left(\rho_{c}\right)$ were often reduced when using the H-B scale compared with NPEs. There was no consistent effect of converting NPEs to NPEH-B midpoint values compared with actual H-B values. Inter-rater reliability using the H-B scale was never better than NPEs. Bootstrap analysis indicated no difference in the length of time needed to assess disease but regression analysis suggested that raters who were inherently fast in assessing disease with NPEs were often slower when using the H-B scale; conversely, raters who were slow assessing with NPEs were often faster when using the H-B scale. Thus, there appears to be no advantage in accuracy or reliability or reduction in time when inexperienced or experienced raters used a category rating scale to assess pecan scab.
\end{abstract} Neither experienced nor inexperienced raters were consistently better
Pecan scab (caused by the fungus Fusicladium effusum G. Winter) is the most destructive disease of pecan (Carya illinoinensis Koch.), a crop widely grown throughout the southeastern United States $(27,28)$. Typically, symptoms of pecan scab are characterized by discrete dark gray to black lesions that develop on shoots, leaves, or fruit. The lesions can be small but may expand and coalesce, causing symptoms over large surface areas of the leaf, fruit, or shoots. Loss in quality of the nut and loss in yield result from disease development on the fruit and, in years when disease is severe, fruit abortion can also occur, resulting in complete yield loss $(12,26)$.

Pecan scab severity on leaves and fruit has been estimated using category scales $(12,15)$, estimates of the area diseased to the nearest percent (3), and also with the aid of standard area diagrams (29). Standard area diagrams have been shown to improve the accuracy and reliability of pecan scab assessments but the accuracy and reliability of estimates of pecan scab using category scales has not been investigated (2). In the context of disease severity, the accuracy of an estimate can be defined as the closeness of that estimate to the actual value $(10,18,22)$ and the reliability of an estimate can be defined as the extent to which the same estimate is obtained when the sample is again presented to a rater under different conditions $(10,18,22)$. The importance of these terms is realized because disease severity estimates are only useful if they provide a realistic measure of the actual disease severity.

The Horsfall-Barratt (H-B) scale and its derivatives are interval scales that partition severity into defined categories. The original $\mathrm{H}-\mathrm{B}$ scale is divided into a total of 12 categories, with 6 logarithmically increasing category sizes up to $50 \%$ severity and 6

Corresponding author: C. H. Bock, E-mail: clive.bock@ars.usda.gov

Accepted for publication 11 November 2012.

http://dx.doi.org/10.1094/PDIS-07-12-0642-RE

This article is in the public domain and not copyrightable. It may be freely reprinted with customary crediting of the source. The American Phytopathological Society, 2013. logarithmically decreasing category sizes up to $100 \%$ (14). The scale was developed to resolve a misconceived notion that the accuracy of a rater's estimate was logarithmically related to the actual severity of disease $(14,20)$. Many similar scales have been developed based on the H-B scale $(1,5,11,15,18,25)$, including the Hunter-Roberts scale for rating pecan scab (15), often with the assumption that raters might improve their accuracy or reliability or be faster compared with using a percent scale (0 to 100\%).

However, over the last 30 years, the basis for these nonlinear scales has been questioned and recent data provides evidence that logarithmic category scales do not improve accuracy or reliability compared with taking nearest percent estimates (NPEs). Under some circumstances, category scales might even reduce the accuracy and reliability of individual assessments $(4,5,8,11,13,18-21)$. Furthermore, only a few studies have compared the H-B scale or its derivatives with assessment methods that estimate disease severity to the nearest percent ( 0 to $100 \%$ by $1 \%$ increments) $(1,4,19)$. Two of these studies did not use true H-B category estimates but, instead, used converted H-B value by back-converting NPEs. Whether NPEs converted to $\mathrm{H}-\mathrm{Bs}$ are true surrogates for $\mathrm{H}-\mathrm{B}$ assessments is open to question. Nonetheless, all three studies found that either the H-B scale or its derivatives did not improve accuracy and reliability or that it was detrimental to the accuracy and reliability of the severity estimates.

A log-based scale was recommended and used to assess pecan scab $(2,15)$ but whether this scale offers any advantage to using NPEs for pecan scab severity estimates has not been ascertained. Furthermore, rater experience (defined broadly as knowledge of the disease symptoms and training in disease severity assessment) has been found to influence both accuracy and reliability of assessments of disease severity $(1,7,19,21,23)$; but whether or not rater experience has any effect when using rating scales has not been determined. Furthermore, in large experiments, there might be a need for more than one rater to assess disease; therefore, the effects of category scales compared with NPEs on inter-rater reliability should be addressed. Finally, there is no information on the relative time needed to assess disease by raters using either a log-based scale or by assessing disease by NPEs. Considering the importance of obtaining accurate and reliable disease severity estimates for 
pecan scab, we sought to investigate the effect of rating scales on the accuracy and reliability of pecan scab assessment, and the time required for experienced and inexperienced raters to perform disease assessments.

The specific objectives of this study were to (i) compare the accuracy and precision of NPEs and log-based disease assessments using the $\mathrm{H}-\mathrm{B}$ scale by experienced and inexperienced raters, (ii) ascertain the frequency of correct H-B scale category estimates by inexperienced and experienced raters, (iii) compare the inter-rater reliability of assessments performed by inexperienced and experienced raters, and (iv) compare time required to perform disease assessments for both the H-B category scale and NPE rating methods.

\section{Materials and Methods}

Disease assessment. Two groups of five inexperienced raters who had never assessed disease severity before and one group of experienced raters (who were trained in plant pathology and had more than 15 years of experience in assessing disease severity) were asked to assess two cohorts of 40 images of scab on pecan fruit valves. The first cohort of images was assessed by one group of inexperienced raters (raters 1 to 5), and by the group of experienced raters (raters 11 to 15). The second cohort of images was assessed by the second group of inexperienced raters (raters 6 to 10) and by the same group of experienced raters (which, for the second cohort, were numbered raters 16 to 20). For the first assessment of each cohort, the raters were instructed to assess disease using the NPE method and, for the second assessment, each group was instructed to estimate disease using the $\mathrm{H}-\mathrm{B}$ category scale (where 0 to 11 represented $0,0^{+}$to $3,3^{+}$to $6,6^{+}$to $12,12^{+}$to 25 , $25^{+}$to $50,50^{+}$to $75,75^{+}$to $87,87^{+}$to $94,94^{+}$to $97,97^{+}$to 100 , and 100 , respectively).

All raters received the same verbal instructions and reference sheet immediately prior to performing assessments. The verbal instructions described the symptoms of pecan scab and, for the first assessment, instructions on the NPE method to delineate disease to estimate the severity in percent from 0 to $100 \%$ to the nearest $1 \%$. For the H-B scale, the nonlinear nature of the scale was described, and raters were asked to assign values based on their best impression as into which category they believed the disease severity estimate should be binned. For the first assessment, raters received an accompanying instruction sheet with symptoms of the disease describing NPEs and, for the second assessment, raters were provided with a copy of the H-B category scale, with percent ranges in each category defined. All inexperienced raters completed the two separate assessments within $1 \mathrm{~h}$ of each other but the NPE assessments by the experienced raters were made up to 1 year prior to the $\mathrm{H}-\mathrm{B}$ estimates. All raters were instructed to record their start time and end time for each assessment of the cohort of images.

Measurement of actual values. Actual values of disease for images of pecan valves were measured by image analysis using Assess V2.0 (16), as described by Yadav et al. (29). When comparing estimates to actual values, the concept of agreement was defined as the product of precision (defined as variability in the estimates) and accuracy (18). Prior to analysis, the H-B data were converted to the midpoint values $(9,24)$ to satisfy the requirements of parametric analysis. To explore any effect of conversion, the NPEs were converted to the equivalent category of the H-B scale (NPEHB) prior to converting back to the midpoint value of the percent scale.

Data analysis. All data were analyzed using SAS V9.2 (SAS Systems) and MS Excel 2007. NPEs, H-B midpoint converted, and NPEH-B midpoint converted severity data were compared with actual values for each image and rater in each group using Lin's concordance correlation (LCC) to investigate agreement with the actual values $(6,17,19)$. The component statistics of LCC were compared among methods or rater experience, including bias $(v=$ scale bias and $\mu=$ location bias $)$, accuracy $\left(\mathrm{C}_{\mathrm{b}}=\right.$ the correction factor), precision ( $r=$ Pearson's correlation coefficient), and overall agreement (Lin's concordance correlation coefficient $[$ LCCC $]=$ $\rho_{c}$ ). Regression analysis (PROC REG) was used to compare the pairwise LCC statistics from the three different methods of assessment (NPEs, H-B, and NPEH-B). The frequency of correct category binning (based on actual values converted to the H-B category) was determined for the H-B assessment method and the NPEH-B data. The relationship between the time required to perform assessments by NPEs and the difference in time to perform assessments (NPE $\mathrm{H}-\mathrm{B}$ ) was analyzed using linear regression analysis.

Inter-rater reliability for each method (NPEs, H-B, and NPEHB) for experienced and inexperienced raters was analyzed with the intra-class correlation coefficient $(\rho)$ using a two-way randomeffects ANOVA (PROC ANOVA) with arcsine-transformed data

Table 1. Mean and standard deviation (Stdev) of pecan scab severity estimates on pecan fruit valves ${ }^{\mathrm{a}}$

\begin{tabular}{|c|c|c|c|c|c|c|c|}
\hline \multirow[b]{2}{*}{ Image cohort, rater $^{b}$} & \multirow[b]{2}{*}{ Rater number } & \multicolumn{2}{|c|}{ NPE } & \multicolumn{2}{|c|}{ H-B } & \multicolumn{2}{|c|}{ NPEH-B } \\
\hline & & Mean & Stdev & Mean & Stdev & Mean & Stdev \\
\hline \multicolumn{8}{|l|}{ Cohort 1} \\
\hline \multirow[t]{5}{*}{ Inexperienced } & 1 & 41.1 & 28.6 & 36.8 & 34.9 & 39.7 & 28.2 \\
\hline & 2 & 23.4 & 27.4 & 27.4 & 32.6 & 23.2 & 27.6 \\
\hline & 3 & 17.6 & 20.3 & 16.6 & 22.0 & 17.9 & 19.9 \\
\hline & 4 & 19.6 & 23.7 & 13.4 & 20.9 & 17.4 & 20.6 \\
\hline & 5 & 20.0 & 28.3 & 18.4 & 27.1 & 20.3 & 29.3 \\
\hline \multirow[t]{5}{*}{ Experienced } & 11 & 16.4 & 22.5 & 16.4 & 22.1 & 16.2 & 21.9 \\
\hline & 12 & 34.3 & 24.9 & 30.3 & 28.1 & 32.5 & 24.7 \\
\hline & 13 & 25.3 & 25.1 & 28.6 & 28.9 & 24.7 & 25.2 \\
\hline & 14 & 23.3 & 22.9 & 21.4 & 19.3 & 23.1 & 21.5 \\
\hline & 15 & 25.6 & 25.6 & 20.0 & 23.1 & 25.4 & 25.4 \\
\hline \multicolumn{8}{|l|}{ Cohort 2} \\
\hline \multirow[t]{5}{*}{ Inexperienced } & 6 & 26.7 & 31.7 & 37.8 & 31.6 & 25.8 & 31.7 \\
\hline & 7 & 33.0 & 28.2 & 28.9 & 29.4 & 34.3 & 28.4 \\
\hline & 8 & 21.8 & 25.8 & 20.4 & 23.3 & 22.2 & 25.7 \\
\hline & 9 & 20.0 & 24.6 & 20.6 & 27.8 & 19.5 & 25.4 \\
\hline & 10 & 22.0 & 23.1 & 25.1 & 28.3 & 21.1 & 22.7 \\
\hline \multirow[t]{5}{*}{ Experienced } & 16 & 19.4 & 26.0 & 17.0 & 22.6 & 19.7 & 26.3 \\
\hline & 17 & 21.5 & 26.6 & 33.1 & 29.9 & 21.4 & 25.9 \\
\hline & 18 & 24.4 & 28.2 & 29.1 & 30.4 & 23.9 & 27.9 \\
\hline & 19 & 24.3 & 23.5 & 21.3 & 23.6 & 24.5 & 23.2 \\
\hline & 20 & 22.5 & 26.8 & 23.2 & 27.5 & 22.8 & 26.9 \\
\hline
\end{tabular}

${ }^{a}$ Actual values of disease severity for set $1=20.07$ (stdev $=22.19$ ) and for set $2=20.83$ (stdev 23.66). Assessments made using either nearest percent estimates (NPEs), the Horsfall-Barratt (H-B) scale, or the converted values of the NPEs to the H-B scale (NPEH-B).

b Raters assessed two sets of 40 images (cohorts 1 and 2). Raters were inexperienced or experienced. 
(arcsine $\sqrt{[\text { estimate } \% / 100]) ~(19) . ~ T h e ~ i n t r a-c l a s s ~ c o r r e l a t i o n ~ c o e f f i-~}$ cient $(\rho)$ was calculated using the variance components $\sigma_{\text {leaf }}^{2}$, $\sigma_{\text {rater }}^{2}$, and $\sigma_{\text {error }}^{2}: \rho=\sigma_{\text {leaf }}^{2} /\left(\sigma_{\text {leaf }}^{2}+\sigma_{\text {rater }}^{2}+\sigma_{\text {error }}^{2}\right)$. Inter-rater reliability was also analyzed for each method using regression analysis and calculating the coefficient of determination $\left(R^{2}\right)$ and coefficient of variation $(\mathrm{CV})$ to quantify the relationships for each method (NPEs, H-B, and NPEH-B) and compare between each pair of methods ([NPE - H-B], [H-B - NPEH-B], and [NPE NPEH-B]). The $C V$ is a unitless measure of variation, and is calculated as (mean square error/mean) $\times 100$.

For all variables (LCC agreement statistics, inter-rater reliability, and time to perform assessments), the difference between the means for assessment methods was calculated (method $1-$ method
2) and an equivalence test $(1,29,30)$ was used to calculate $95 \%$ confidence intervals (CIs) for the statistic by bootstrapping using the percentile method. For an equivalence test, the null hypothesis is the converse of $\mathrm{H}_{0}$ (i.e., the null hypothesis is nonequivalence). In all analyses, 2,000 balanced bootstrap samples were performed and $95 \%$ CIs calculated using PROC SURVEYSELECT/PROC UNIVARIATE. Because the $95 \%$ CIs were calculated on the difference between the means, CIs that did not include zero were considered significantly different.

\section{Results}

Accuracy, precision, and agreement. In both cohorts of images assessed by both inexperienced and experienced raters, some

Table 2. Bias, accuracy, and agreement measures using Lin's concordance correlation (LCC), and time taken for experienced and inexperienced raters to assess pecan valve images showing symptoms of pecan scab using the nearest percent estimate method for cohort 1 and $2^{\mathrm{a}}$

\begin{tabular}{|c|c|c|c|c|c|c|c|c|c|c|c|c|c|c|c|c|c|c|c|c|}
\hline \multirow[b]{4}{*}{$\mathrm{LCC}^{\mathrm{b}}$} & \multicolumn{20}{|c|}{ Rater experience } \\
\hline & \multicolumn{10}{|c|}{ Inexperienced } & \multicolumn{10}{|c|}{ Experienced } \\
\hline & \multicolumn{5}{|c|}{ Cohort 1} & \multicolumn{5}{|c|}{ Cohort 2} & \multicolumn{5}{|c|}{ Cohort 1} & \multicolumn{5}{|c|}{ Cohort 2} \\
\hline & 1 & 2 & 3 & 4 & 5 & 6 & 7 & 8 & 9 & 10 & 11 & 12 & 13 & 14 & 15 & 16 & 17 & 18 & 19 & 20 \\
\hline$v$ & 1.29 & 1.23 & 0.91 & 1.07 & 1.27 & 1.34 & 1.19 & 1.09 & 1.04 & 0.98 & 1.01 & 1.12 & 1.13 & 1.03 & 1.15 & 1.10 & 1.12 & 1.19 & 0.99 & 1.13 \\
\hline$\mu$ & 0.84 & 0.14 & -0.12 & -0.02 & 0.00 & 0.21 & 0.47 & 0.04 & -0.04 & 0.05 & -0.17 & 0.60 & 0.22 & 0.14 & 0.23 & -0.06 & 0.03 & 0.14 & 0.15 & 0.07 \\
\hline $\mathrm{C}_{\mathrm{b}}$ & 0.72 & 0.97 & 0.99 & 1.00 & 0.97 & 0.94 & 0.89 & 1.00 & 1.00 & 1.00 & 0.99 & 0.84 & 0.97 & 0.99 & 0.96 & 0.99 & 0.99 & 0.98 & 0.99 & 0.99 \\
\hline$r$ & 0.78 & 0.96 & 0.90 & 0.72 & 0.97 & 0.96 & 0.96 & 0.97 & 0.94 & 0.78 & 0.94 & 0.92 & 0.94 & 0.97 & 0.95 & 0.97 & 0.94 & 0.97 & 0.96 & 0.97 \\
\hline$\rho_{c}$ & 0.57 & 0.93 & 0.89 & 0.72 & 0.94 & 0.90 & 0.86 & 0.96 & 0.94 & 0.78 & 0.93 & 0.77 & 0.91 & 0.96 & 0.92 & 0.96 & 0.94 & 0.94 & 0.95 & 0.96 \\
\hline $\mathrm{T}(\min )$ & 7.0 & 10.0 & 6.0 & 6.0 & 7.0 & 10.0 & 6.0 & 9.0 & 8.0 & 10.0 & 5.0 & $\ldots$ & 3.0 & 8.0 & 10.0 & 11.0 & 4.0 & 9.0 & 10.0 & 11.0 \\
\hline
\end{tabular}

${ }^{a}$ Raters assessed two sets of 40 images (cohorts 1 and 2); $\ldots=$ missing value.

${ }^{\mathrm{b}}$ LCC variables: $v=$ scale bias, or slope shift $(1=$ no bias relative to the concordance line $) ; \mu=$ location bias, or height shift $(0=$ no bias relative to the concordance line); $\mathrm{C}_{\mathrm{b}}=$ correction factor, which measures how far the best-fit line deviates from $45^{\circ}$ and, thus, is a measure of accuracy; $r=$ correlation coefficient, which measures precision; $\rho_{\mathrm{c}}=\mathrm{LCC}$ coefficient, which combines both measures of precision $(r)$ and accuracy $\left(\mathrm{C}_{\mathrm{b}}\right)$ to measure the degree of agreement with the true value; and $\mathrm{T}=$ time taken to assess the 40 images in each cohort.

Table 3. Bias, accuracy, and agreement measures using Lin's concordance correlation (LCC), and time taken for experienced and inexperienced raters to assess pecan valve images showing symptoms of pecan scab using the 12-point Horsfall-Barratt category scale ${ }^{\mathrm{a}}$

\begin{tabular}{|c|c|c|c|c|c|c|c|c|c|c|c|c|c|c|c|c|c|c|c|c|}
\hline \multirow[b]{4}{*}{$\mathbf{L C C}^{\mathrm{b}}$} & \multicolumn{20}{|c|}{ Rater experience } \\
\hline & \multicolumn{10}{|c|}{ Inexperienced } & \multicolumn{10}{|c|}{ Experienced } \\
\hline & \multicolumn{5}{|c|}{ Cohort 1} & \multicolumn{5}{|c|}{ Cohort 2} & \multicolumn{5}{|c|}{ Cohort 1} & \multicolumn{5}{|c|}{ Cohort 2} \\
\hline & 1 & 2 & 3 & 4 & 5 & 6 & 7 & 8 & 9 & 10 & 11 & 12 & 13 & 14 & 15 & 16 & 17 & 18 & 19 & 20 \\
\hline v & 1.57 & 1.47 & 0.99 & 0.94 & 1.22 & 1.34 & 1.24 & 0.99 & 1.18 & 1.19 & 1.00 & 1.27 & 1.30 & 0.87 & 1.04 & 0.96 & 1.26 & 1.28 & 1.00 & 1.16 \\
\hline$\mu$ & 0.60 & 0.27 & -0.16 & -0.31 & -0.07 & 0.62 & 0.31 & -0.02 & -0.01 & 0.17 & -0.17 & 0.41 & 0.34 & 0.06 & 0.00 & -0.17 & 0.46 & 0.31 & 0.02 & 0.09 \\
\hline $\mathrm{C}_{\mathrm{b}}$ & 0.78 & 0.90 & 0.99 & 0.95 & 0.98 & 0.81 & 0.93 & 1.00 & 0.99 & 0.97 & 0.99 & 0.90 & 0.92 & 0.99 & 1.00 & 0.99 & 0.88 & 0.93 & 1.00 & 0.98 \\
\hline$r$ & 0.75 & 0.86 & 0.93 & 0.77 & 0.92 & 0.86 & 0.95 & 0.94 & 0.96 & 0.94 & 0.95 & 0.89 & 0.93 & 0.94 & 0.98 & 0.88 & 0.94 & 0.95 & 0.94 & 0.97 \\
\hline$\rho_{\mathrm{c}}$ & 0.59 & 0.77 & 0.92 & 0.73 & 0.90 & 0.70 & 0.89 & 0.94 & 0.95 & 0.91 & 0.94 & 0.80 & 0.85 & 0.93 & 0.98 & 0.87 & 0.83 & 0.88 & 0.94 & 0.96 \\
\hline $\mathrm{T}(\min )$ & 10.0 & 4.0 & 5.0 & 6.0 & 10.0 & 7.0 & 8.0 & 9.0 & 7.0 & 16.0 & 5.0 & $\ldots$ & 6.0 & 9.0 & 5.0 & 4.0 & 9.0 & 4.0 & 10.0 & 6.0 \\
\hline
\end{tabular}

${ }^{a}$ Raters assessed two sets of 40 images (cohorts 1 and 2$) ; \ldots=$ missing value.

${ }^{\mathrm{b}}$ LCC variables: $v=$ scale bias, or slope shift $(1=$ no bias relative to the concordance line $) ; \mu=$ location bias, or height shift $(0=$ no bias relative to the concordance line); $\mathrm{C}_{\mathrm{b}}=$ correction factor, which measures how far the best-fit line deviates from $45^{\circ}$ and, thus, is a measure of accuracy; $r=$ correlation coefficient, which measures precision; $\rho_{\mathrm{c}}=\mathrm{LCC}$ coefficient, which combines both measures of precision $(r)$ and accuracy $\left(\mathrm{C}_{\mathrm{b}}\right)$ to measure the degree of agreement with the true value; and $\mathrm{T}=$ time taken to assess the 40 images in each cohort.

Table 4. Bias, accuracy, and agreement measures using Lin's concordance correlation (LCC) for estimates of severity of scab on pecan fruit by experienced and inexperienced raters based on the Horsfall-Barratt scale back-converted mid-point data from the original nearest percent estimates ${ }^{\mathrm{a}}$

\begin{tabular}{|c|c|c|c|c|c|c|c|c|c|c|c|c|c|c|c|c|c|c|c|c|}
\hline \multirow[b]{4}{*}{$\mathrm{LCC}^{\mathbf{b}}$} & \multicolumn{20}{|c|}{ Rater experience } \\
\hline & \multicolumn{10}{|c|}{ Inexperienced } & \multicolumn{10}{|c|}{ Experienced } \\
\hline & \multicolumn{5}{|c|}{ Cohort 1} & \multicolumn{5}{|c|}{ Cohort 2} & \multicolumn{5}{|c|}{ Cohort 1} & \multicolumn{5}{|c|}{ Cohort 2} \\
\hline & 1 & 2 & 3 & 4 & 5 & 6 & 7 & 8 & 9 & 10 & 11 & 12 & 13 & 14 & 15 & 16 & 17 & 18 & 19 & 20 \\
\hline$v$ & 1.27 & 1.24 & 0.90 & 0.93 & 1.32 & 1.34 & 1.20 & 1.09 & 1.07 & 0.96 & 0.99 & 1.11 & 1.14 & 0.97 & 1.14 & 1.11 & 1.09 & 1.18 & 0.98 & 1.14 \\
\hline$\mu$ & 0.78 & 0.12 & -0.10 & -0.13 & 0.01 & 0.18 & 0.52 & 0.06 & -0.05 & 0.01 & -0.17 & 0.53 & 0.20 & 0.14 & 0.22 & -0.04 & 0.02 & 0.12 & 0.16 & 0.08 \\
\hline $\mathrm{C}_{\mathrm{b}}$ & 0.75 & 0.97 & 0.99 & 0.99 & 0.96 & 0.94 & 0.87 & 0.99 & 1.00 & 1.00 & 0.98 & 0.87 & 0.97 & 0.99 & 0.97 & 0.99 & 1.00 & 0.98 & 0.99 & 0.99 \\
\hline$r$ & 0.82 & 0.95 & 0.89 & 0.70 & 0.96 & 0.96 & 0.95 & 0.95 & 0.94 & 0.81 & 0.93 & 0.91 & 0.93 & 0.96 & 0.84 & 0.97 & 0.95 & 0.97 & 0.94 & 0.95 \\
\hline$\rho_{\mathrm{c}}$ & 0.61 & 0.92 & 0.88 & 0.69 & 0.92 & 0.91 & 0.82 & 0.95 & 0.94 & 0.81 & 0.92 & 0.79 & 0.90 & 0.95 & 0.81 & 0.96 & 0.95 & 0.95 & 0.93 & 0.94 \\
\hline
\end{tabular}

a Raters assessed two sets of 40 images (cohorts 1 and 2).

${ }^{b}$ LCC variables: $v=$ scale bias, or slope shift $(1=$ no bias relative to the concordance line $)$; $\mu=$ location bias, or height shift $(0=$ no bias relative to the concordance line); $\mathrm{C}_{\mathrm{b}}=$ correction factor, which measures how far the best-fit line deviates from $45^{\circ}$ and, thus, is a measure of accuracy; $r=$ correlation coefficient, which measures precision; and $\rho_{c}=$ LCC coefficient, which combines both measures of precision $(r)$ and accuracy $\left(\mathrm{C}_{\mathrm{b}}\right)$ to measure the degree of agreement with the true value. 
disease assessments were close to the actual mean, with standard deviations similar to the actual standard deviation (Table 1). However, among both inexperienced and experienced raters, there were some raters who overestimated disease severity. For example, in image cohort 1 , inexperienced rater 1 and experienced rater 2 both overestimated disease severity. Overestimates of the mean were more frequent than underestimates for these samples. With most raters, the H-B and NPEH-B assessment were less than $3.5 \%$ different compared with the NPE. The most extreme differences were for image cohort 2 , rater 1 and rater 17 , who overestimated disease severity by 11.1 and $11.6 \%$, respectively, using the H-B scale compared with NPEs (the NPE being the most accurate).

The LCC analysis (bias, accuracy, precision, and agreement) and time taken for the assessment for each rater using NPEs, the H-B scale, and the NPEH-B are shown in Tables 2, 3, and 4, respectively. Using the NPE method, the measures of agreement were consistently high $\left(\rho_{c} \geq 0.86\right)$, except for inexperienced raters 1,4 , and 10 and experienced rater 12, suggesting that both inexperienced and experienced raters in this study were relatively accurate and precise using the NPE method to assess disease severity (Table 2). Measures of accuracy $\left(\mathrm{C}_{\mathrm{b}}\right)$ among inexperienced raters were also high $\left(C_{b} \geq 0.89\right)$, except for rater $1\left(C_{b}=0.72\right)$. Among experienced raters, only rater $12\left(C_{b}=0.84\right)$ had accuracy $<0.97$. Experienced rater's assessments were consistently precise $(r$ $\geq 0.92$ ), whereas the precision of inexperienced raters ranged from $r=0.72$ to 0.97 . Neither cohort of images nor experienced or inexperienced raters as a group had consistently higher or lower values for any measure of accuracy or precision. Similarly, the time needed by raters to assess diseased images was not significantly different for experienced ( 6 to $10 \mathrm{~min}$ ) versus inexperienced ( 3 to $11 \mathrm{~min}$ ) raters for either cohort of images.

Disease assessments using the H-B scale provided measures of agreement that were more variable among inexperienced raters $\left(\rho_{c}\right.$ $=0.59$ to 0.95$)$ compared with experienced raters $\left(\rho_{\mathrm{c}}=0.80\right.$ to 0.98 ) but neither group was consistently better (Table 3 ). Only specific raters $(1,2,12$, and 13$)$ exhibited a greater scale bias com-
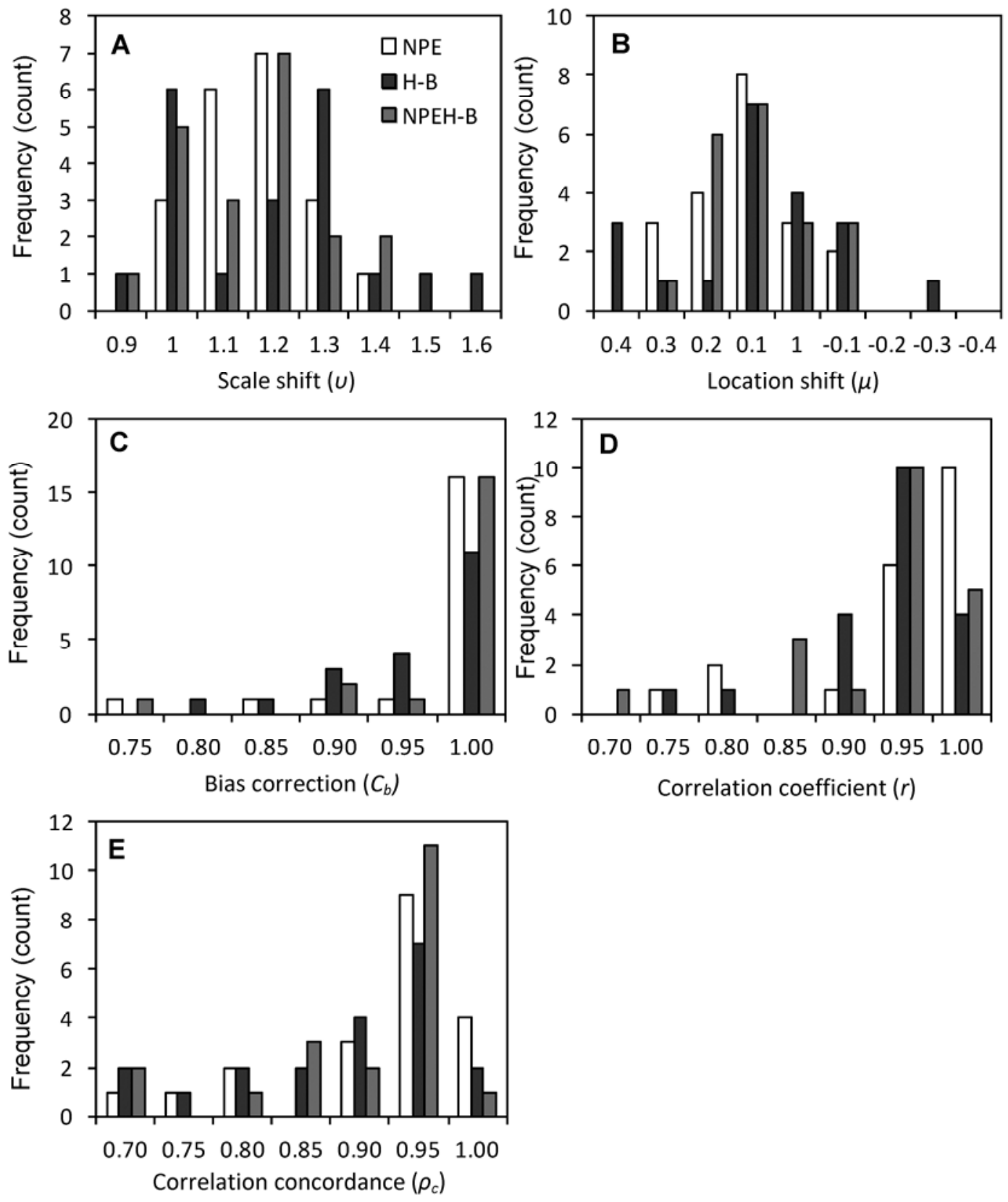

Fig. 1. Frequency of bias, precision, and agreement values using either the nearest percent estimation (NPE) method, the Horsfall-Barratt category scale (H-B), or conversion of the NPE to the H-B mid-points (NPEH-B) for estimates of disease severity on two sets of 40 images of scab-diseased pecan fruit valves. A, Scale bias; B, location bias; C, correction factor; $\mathbf{D}$, correlation coefficient; $\mathbf{E}$, Lin's concordance correlation coefficient. 
pared with the NPE estimates. Measures of accuracy $\left(C_{b}\right)$ using the H-B scale ranged from 0.78 to 1.00 for inexperienced raters and 0.88 to 1.00 for experienced raters, with neither group having consistently higher values. Among inexperienced raters, precision $(r)$ ranged from 0.75 to 0.96 and, among experienced raters, from 0.89 to 0.98 but neither group was consistently higher. There was no consistent difference in the time taken by inexperienced (4 to 16 $\mathrm{min}$ ) or experienced raters (4 to $10 \mathrm{~min}$ ) using the $\mathrm{H}-\mathrm{B}$ scale.

Converting the NPEs to NPEH-B values resulted in measures of agreement $\geq 0.82\left(\rho_{c}\right)$ for all raters, with the exception of inexperienced raters 1, 4, and 10 and experienced raters 12 and 15 (Table 4). Measures of accuracy $\left(C_{b}\right)$ among inexperienced raters were also high $\left(C_{b} \geq 0.87\right)$, except for rater $1\left(C_{b}=0.75\right)$. Among experienced raters, only rater $12\left(\mathrm{C}_{b}=0.87\right)$ had accuracy $<0.97$. NPEH$\mathrm{B}$ values of experienced raters' estimates were consistently precise $(r \geq 0.91)$, with the exception of rater $15(r=0.84)$, whereas the range in precision by inexperienced raters was greater $(r=0.70$ to 0.96). Neither cohort of images nor experienced or inexperienced raters as a group had consistently higher or lower values for any measure.

The frequency of values for each LCC statistic using NPEs, the H-B method, or NPEH-B values indicated some similarities among the different methods (Fig. 1). The most extreme values of scale bias $(v)$ occurred when raters used the H-B category scale. Frequencies of location bias $(\mu)$ were similar, although the H-B scale also had the most extreme values. The frequency of very high accuracy $\left(C_{b} \geq 0.95\right)$ was greatest with NPEs (and the NPEH-B data), and high precision $(r>0.95)$ was consistently greatest for the NPE data. Frequency of greatest agreement $\left(\rho_{c}>0.90\right)$ was highest for the NPE method and the NPEH-B values.

Comparison of methods with inexperienced and experienced raters. Both inexperienced and experienced raters either over- or underestimated the true assessment category when using the $\mathrm{H}-\mathrm{B}$ category scale or the NPEH-B values (Table 5). Individual raters varied in the proportion of over- or underestimates. The percentage of incorrect category estimates ranged from 37.5 to 80.0 and 37.5 to $72.5 \%$ incorrect categories for the inexperienced and experienced raters, respectively.

Bootstrap analysis of the difference between the means between NPE and H-B rating methods among inexperienced or experienced raters showed few contrasts based on the LCC statistics (Table 6) There were no significant differences for inexperienced raters in either cohort. Among experienced raters, only for cohort 2 was both precision $(r)$ and agreement $\left(\rho_{c}\right)$ reduced by using the H-B category scale.

Using bootstrapping to compare the difference between the means for NPEs and NPEH-B data indicated some differences among experienced raters but not inexperienced raters (Table 7). Due to NPEH-B conversion, the experienced raters in cohort 1 had improved location $(\mu)$ bias but a reduction in the precision $(r)$ of estimates. There was no significant effect among experienced raters when assessing cohort 2 images.

Table 5. Frequency of over- and underestimates using the Horsfall-Barratt (H-B) scale for raters estimating the severity of pecan scab on valves of pecan fruit

\begin{tabular}{|c|c|c|c|c|c|c|c|c|c|c|c|c|c|c|c|c|c|c|c|c|c|}
\hline \multirow[b]{3}{*}{ Rating $^{\mathbf{a}}$} & \multirow[b]{3}{*}{ Accuracy $^{b}$} & \multicolumn{10}{|c|}{ Inexperienced } & \multicolumn{10}{|c|}{ Experienced } \\
\hline & & \multicolumn{5}{|c|}{ Cohort 1} & \multicolumn{5}{|c|}{ Cohort 2} & \multicolumn{5}{|c|}{ Cohort 1} & \multicolumn{5}{|c|}{ Cohort 2} \\
\hline & & 1 & 2 & 3 & 4 & 5 & 6 & 7 & 8 & 9 & 10 & 11 & 12 & 13 & 14 & 15 & 16 & 17 & 18 & 19 & 20 \\
\hline \multirow[t]{4}{*}{ H-B } & Over & 23 & 15 & 4 & 3 & 6 & 27 & 20 & 11 & 7 & 16 & 2 & 24 & 18 & 15 & 7 & 9 & 27 & 21 & 12 & 11 \\
\hline & Correct & 9 & 14 & 18 & 10 & 15 & 11 & 18 & 17 & 18 & 16 & 21 & 14 & 19 & 19 & 22 & 15 & 11 & 14 & 21 & 22 \\
\hline & Under & 8 & 11 & 18 & 27 & 19 & 2 & 2 & 12 & 15 & 8 & 17 & 2 & 3 & 6 & 8 & 16 & 2 & 5 & 7 & 7 \\
\hline & Incorr $(\%)$ & 77.5 & 65 & 55 & 75 & 62.5 & 72.5 & 55 & 57.5 & 55 & 60 & 47.5 & 65 & 52.5 & 52.5 & 37.5 & 62.5 & 72.5 & 65 & 47.5 & 45 \\
\hline \multirow[t]{4}{*}{ NPEH-B } & Over & 32 & 11 & 9 & 9 & 8 & 15 & 32 & 10 & 7 & 11 & 3 & 29 & 13 & 16 & 12 & 4 & 12 & 12 & 18 & 12 \\
\hline & Correct & 8 & 20 & 16 & 12 & 14 & 15 & 7 & 20 & 21 & 25 & 18 & 11 & 25 & 21 & 21 & 22 & 18 & 18 & 16 & 16 \\
\hline & Under & 0 & 9 & 15 & 19 & 18 & 10 & 1 & 10 & 12 & 4 & 19 & 0 & 2 & 3 & 4 & 14 & 10 & 10 & 6 & 12 \\
\hline & Incorr $(\%)$ & 80 & 50 & 60 & 70 & 65 & 62.5 & 82.5 & 50 & 47.5 & 37.5 & 55 & 72.5 & 37.5 & 47.5 & 40 & 45 & 55 & 55 & 60 & 60 \\
\hline
\end{tabular}

a Rating method. Inexperienced or experienced raters made assessments using either the H-B scale or the converted values of the nearest percent estimates (NPEs) to the H-B scale (NPEH-B). Raters assessed two sets of 40 images (cohorts 1 and 2).

${ }^{\mathrm{b}}$ Over $=$ overestimate, Under $=$ underestimate, and Incorr $=$ incorrect.

Table 6. Mean concordance statistics (bias, accuracy, precision, and agreement) with bootstrap analysis of the differences between means when using the nearest percent estimate (NPEs) method versus the Horsfall-Barratt (H-B) category scale to assess scab severity on pecan fruit valves ${ }^{\mathrm{a}}$

\begin{tabular}{|c|c|c|c|c|c|c|c|c|}
\hline \multirow[b]{3}{*}{ Rater, $\mathbf{L C C}^{\mathbf{b}}$} & \multicolumn{4}{|c|}{ Cohort 1} & \multicolumn{4}{|c|}{ Cohort 2} \\
\hline & \multicolumn{2}{|c|}{ Mean } & \multirow[b]{2}{*}{ Diff } & \multirow[b]{2}{*}{ 95\% CIs } & \multicolumn{2}{|c|}{ Mean } & \multirow[b]{2}{*}{ Diff } & \multirow[b]{2}{*}{ 95\% CIs } \\
\hline & NPE & H-B & & & NPE & H-B & & \\
\hline \multicolumn{9}{|l|}{ Inexperienced } \\
\hline$v$ & 1.15 & 1.24 & -0.083 & $-0.224-0.056$ & 1.13 & 1.19 & -0.062 & $-0.154-0.032$ \\
\hline$\mu$ & 0.17 & 0.07 & 0.102 & $-0.023-0.230$ & 0.15 & 0.21 & -0.068 & $-0.258-0.083$ \\
\hline $\mathrm{C}_{\mathrm{b}}$ & 0.93 & 0.92 & 0.010 & $-0.029-0.048$ & 0.92 & 0.93 & 0.024 & $-0.024-0.082$ \\
\hline$r$ & 0.87 & 0.85 & 0.020 & $-0.026-0.066$ & 0.97 & 0.94 & -0.009 & $-0.092-0.058$ \\
\hline$\rho_{c}$ & 0.81 & 0.78 & 0.028 & $-0.022-0.098$ & 0.89 & 0.88 & 0.009 & $-0.08-0.12$ \\
\hline Time (min) & 7.2 & 7.0 & 0.191 & $-2.4-3.2$ & 8.6 & 9.4 & -0.833 & $-3.80-1.60$ \\
\hline \multicolumn{9}{|l|}{ Experienced } \\
\hline$v$ & 1.09 & 1.10 & -0.006 & $-0.126-0.110$ & 1.11 & 1.13 & -0.026 & $-0.100-0.064$ \\
\hline$\mu$ & 0.20 & 0.13 & 0.078 & $-0.034-0.184$ & 0.07 & 0.14 & -0.075 & $-0.270-0.092$ \\
\hline $\mathrm{C}_{\mathrm{b}}$ & 0.95 & 0.96 & -0.011 & $-0.04-0.022$ & 0.99 & 0.96 & 0.032 & $-0.002-0.074$ \\
\hline$r$ & 0.94 & 0.94 & 0.006 & $-0.014-0.026$ & 0.96 & 0.94 & 0.026 & 0.004-0.058 \\
\hline$\rho_{\mathrm{c}}$ & 0.90 & 0.90 & -0.003 & $-0.040-0.036$ & 0.95 & 0.90 & 0.054 & $0.016-0.092$ \\
\hline Time (min) & 6.5 & 6.3 & 0.332 & $-2.25-3.50$ & 9.0 & 6.6 & 2.38 & $-1.60-5.80$ \\
\hline
\end{tabular}

${ }^{\text {a }}$ Diff $=$ mean of the difference between each rating; confidence intervals (CIs) were based on 2,000 bootstrap samples. If the CIs embrace zero, the difference is not significant $(\alpha=0.05)$. Bold text indicates a significant difference.

b Rater experience and Lin's concordance correlation (LCC) statistics: $v=$ scale bias, or slope shift $(1=$ no bias relative to the concordance line); $\mu=$ location bias, or height shift $(0=$ no bias relative to the concordance line $) ; \mathrm{C}_{\mathrm{b}}=$ correction factor, which measures how far the best-fit line deviates from $45^{\circ}$ and, thus, is a measure of accuracy; $r=$ correlation coefficient, which measures precision; $\rho_{c}=$ LCC coefficient, which combines both measures of precision $(r)$ and accuracy $\left(\mathrm{C}_{\mathrm{b}}\right)$ to measure the degree of agreement with the true value; and Time $=$ time taken to assess the 40 images in each cohort. 
The bootstrap analysis of the difference between H-B category scale and NPEH-B converted values indicated that there was a significant difference between the two assessment methods in agreement $\left(\rho_{c}\right)$ for experienced raters assessing cohort 2 images only (Table 8 ). There were no other significant effects of rating method on differences between the means. Regression analyses comparing all pairs of rating methods for each LCC statistic (Table 9; Fig. 2) indicated that the strongest relationship was found between NPE and the NPEH-B data $\left(R^{2}=0.85\right.$ to $0.98, C V=1.1$ to 25.4), whereas comparisons of NPEs to H-B assessments and H-B assessments to NPEH-B conversions had poorer relationships $\left(R^{2}=\right.$ 0.42 to 0.52 and 0.28 to 0.53 and $C V=7.2$ to 121.8 and 5.0 to 140.8 , respectively).

Inter-rater reliability. The ANOVA indicated significant effects of rater and leaf image $(P<0.0001)$ on estimates of disease severity. The inter-rater reliability measured by the intra-class correlation (ICC) coefficient that reliability was greatest for experienced raters using the NPE assessment method (Table 10). According to the ICC, with inexperienced raters for image cohort 2, the H-B scale was equal to NPEs. There was most often less reliability when using NPEH-B data (i.e., values converted from NPEs to the equivalent H-B category) compared with using the NPE method. Based on regression analysis, for each image cohort and experience group, the NPE method was the most reliable, with the highest values for the coefficients of determination $\left(R^{2}=0.65\right.$ to 0.96$)$ and the lowest values for $C V \mathrm{~s}$ (24.1 to 70.5) compared with the $\mathrm{H}$ B category scale $\left(R^{2}=0.60\right.$ to $0.84, C V=41.3$ to 90.8 , respectively) and the NPEH-B data $\left(R^{2}=0.59\right.$ to $0.92, C V=31.5$ to 78.9 , respectively). The bootstrap analysis of the differences in the interrater coefficients of determinations for each method and cohort for experienced and inexperienced raters (Table 11) showed that there were no significant differences among the NPE- and H-B-based assessment methods when assessing cohort 1 images but both inexperienced and experienced raters were more reliable in their assessing using the NPE method when assessing cohort 2 images. Comparing both sets of images, inter-rater reliability was greatest using the NPE method compared with using the NPEH-B results Only experienced raters assessing cohort 2 images had significantly better reliability using the H-B scale compared with NPEH$B$ data. Inter-rater reliability was highest using the NPE method and the NPEH-B data $\left(R^{2}>0.90\right)$. No inter-rater reliabilities $\left(R^{2}\right)$ exceeded 0.95 when using the H-B method (Fig. 3).

Table 7. Mean concordance statistics (bias, accuracy, precision, and agreement) with bootstrap analysis of the difference between means when using the nearest percent estimate (NPEs) method versus the Horsfall-Barratt mid-point converted NPE (NPEH-B) values to assess scab severity on pecan fruit valves ${ }^{\mathrm{a}}$

\begin{tabular}{|c|c|c|c|c|c|c|c|c|}
\hline \multirow[b]{3}{*}{ Rater, LCC $^{\mathbf{b}}$} & \multicolumn{4}{|c|}{ Cohort 1} & \multicolumn{4}{|c|}{ Cohort 2} \\
\hline & \multicolumn{2}{|c|}{ Mean } & \multirow[b]{2}{*}{ Diff } & \multirow[b]{2}{*}{$95 \%$ CIs } & \multicolumn{2}{|c|}{ Mean } & \multirow[b]{2}{*}{ Diff } & \multirow[b]{2}{*}{$95 \%$ CIs } \\
\hline & NPE & NPEH-B & & & NPE & NPEH-B & & \\
\hline \multicolumn{9}{|l|}{ Inexperienced } \\
\hline$v$ & 1.15 & 1.13 & 0.022 & $-0.028-0.086$ & 1.13 & 1.13 & -0.006 & $-0.025-0.010$ \\
\hline$\mu$ & 0.17 & 0.14 & 0.030 & $-0.011-0.076$ & 0.15 & 0.14 & -0.002 & $-0.026-0.030$ \\
\hline $\mathrm{C}_{\mathrm{b}}$ & 0.93 & 0.93 & -0.002 & $-0.016-0.008$ & 0.92 & 0.96 & 0.004 & $0.000-0.012$ \\
\hline$r$ & 0.87 & 0.85 & 0.002 & $-0.020-0.016$ & 0.97 & 0.93 & 0.002 & $-0.016-0.014$ \\
\hline$\rho_{\mathrm{c}}$ & 0.81 & 0.80 & 0.006 & $-0.018-0.022$ & 0.89 & 0.89 & -0.001 & $-0.018-0.018$ \\
\hline \multicolumn{9}{|l|}{ Experienced } \\
\hline$v$ & 1.09 & 1.07 & 0.018 & $0.000-0.042$ & 1.11 & 1.10 & 0.006 & $-0.006-0.018$ \\
\hline$\mu$ & 0.20 & 0.18 & 0.020 & $0.002-0.046$ & 0.07 & 0.07 & -0.002 & $-0.014-0.010$ \\
\hline $\mathrm{C}_{\mathrm{b}}$ & 0.95 & 0.96 & -0.006 & $-0.018-0.004$ & 0.99 & 0.99 & -0.002 & $-0.006-0.000$ \\
\hline$r$ & 0.94 & 0.91 & 0.031 & $0.010-0.070$ & 0.96 & 0.96 & 0.006 & $-0.004-0.016$ \\
\hline$\rho_{\mathrm{c}}$ & 0.90 & 0.87 & 0.025 & $-0.008-0.070$ & 0.95 & 0.95 & 0.004 & $-0.008-0.016$ \\
\hline
\end{tabular}

${ }^{a}$ Diff $=$ mean of the difference between each rating; confidence intervals (CIs) were based on 2,000 bootstrap samples. If the CIs embrace zero, the difference is not significant $(\alpha=0.05)$. Bold text indicates a significant difference.

${ }^{\mathrm{b}}$ Rater experience and Lin's concordance correlation (LCC) statistics:: $v=$ scale bias, or slope shift $(1=$ no bias relative to the concordance line $)$; $\mu=$ location bias, or height shift $\left(0=\right.$ no bias relative to the concordance line); $\mathrm{C}_{\mathrm{b}}=$ correction factor, which measures how far the best-fit line deviates from $45^{\circ}$ and, thus, is a measure of accuracy; $r=$ correlation coefficient, which measures precision; and $\rho_{\mathrm{c}}=\mathrm{LCC}$ coefficient, which combines both measures of precision $(r)$ and accuracy $\left(\mathrm{C}_{\mathrm{b}}\right)$ to measure the degree of agreement with the true value.

Table 8. Mean concordance statistics (bias, accuracy, precision, and agreement) with bootstrap analysis of the difference between means when using the Horsfall-Barratt (H-B) category scale or the Horsfall-Barratt mid-point converted NPE (NPEH-B) values to assess scab severity on pecan fruit valves ${ }^{\mathrm{a}}$

\begin{tabular}{|c|c|c|c|c|c|c|c|c|}
\hline \multirow[b]{3}{*}{ Rater, LCC $^{\mathbf{b}}$} & \multicolumn{4}{|c|}{ Cohort 1} & \multicolumn{4}{|c|}{ Cohort 2} \\
\hline & \multicolumn{2}{|c|}{ Mean } & \multirow[b]{2}{*}{ Diff } & \multirow[b]{2}{*}{$95 \%$ CIs } & \multicolumn{2}{|c|}{ Mean } & \multirow[b]{2}{*}{ Diff } & \multirow[b]{2}{*}{$95 \%$ CIs } \\
\hline & HB & NPEH-B & & & HB & NPEH-B & & \\
\hline \multicolumn{9}{|l|}{ Inexperienced } \\
\hline$v$ & 1.24 & 1.13 & 0.105 & $-0.018-0.230$ & 1.19 & 1.13 & 0.055 & $-0.040-0.154$ \\
\hline$\mu$ & 0.07 & 0.14 & -0.072 & $-0.160-0.036$ & 0.21 & 0.14 & 0.071 & $-0.109-0.280$ \\
\hline $\mathrm{C}_{\mathrm{b}}$ & 0.92 & 0.93 & -0.012 & $-0.044-0.020$ & 0.94 & 0.96 & -0.020 & $-0.082-0.036$ \\
\hline$r$ & 0.85 & 0.85 & -0.018 & $-0.072-0.037$ & 0.93 & 0.93 & 0.011 & $-0.054-0.080$ \\
\hline$\rho_{\mathrm{c}}$ & 0.78 & 0.80 & -0.022 & $-0.086-0.028$ & 0.88 & 0.89 & -0.009 & $-0.116-0.070$ \\
\hline \multicolumn{9}{|l|}{ Experienced } \\
\hline$v$ & 1.10 & 1.07 & 0.025 & $-0.078-0.130$ & 1.13 & 1.10 & 0.032 & $-0.066-0.114$ \\
\hline$\mu$ & 0.13 & 0.18 & -0.058 & $-0.156-0.052$ & 0.14 & 0.07 & 0.073 & $-0.106-0.276$ \\
\hline $\mathrm{C}_{\mathrm{b}}$ & 0.96 & 0.96 & 0.004 & $-0.024-0.026$ & 0.96 & 0.99 & -0.034 & $-0.08-0.002$ \\
\hline$r$ & 0.94 & 0.91 & 0.025 & $-0.016-0.084$ & 0.94 & 0.96 & -0.020 & $-0.056-0.008$ \\
\hline$\rho_{\mathrm{c}}$ & 0.90 & 0.87 & 0.027 & $-0.026-0.102$ & 0.90 & 0.95 & -0.049 & $-0.098--0.002$ \\
\hline
\end{tabular}

${ }^{\mathrm{a}}$ Diff $=$ mean of the difference between each rating; confidence intervals (CIs) were based on 2,000 bootstrap samples. If the CIs embrace zero, the difference is not significant $(\alpha=0.05)$. Bold text indicates a significant difference.

${ }^{\mathrm{b}}$ Rater experience and Lin's concordance correlation (LCC) statistics:: $v=$ scale bias, or slope shift $(1=$ no bias relative to the concordance line); $\mu=$ location bias, or height shift $\left(0=\right.$ no bias relative to the concordance line); $\mathrm{C}_{\mathrm{b}}=$ correction factor, which measures how far the best-fit line deviates from $45^{\circ}$ and, thus, is a measure of accuracy; $r=$ correlation coefficient, which measures precision; and $\rho_{c}=$ LCC coefficient, which combines both measures of precision $(r)$ and accuracy $\left(\mathrm{C}_{\mathrm{b}}\right)$ to measure the degree of agreement with the true value. 
Regression of the difference in the coefficients of determination for pairs of assessment methods showed the same trends as for inter-rater ability (Fig. 4). Experienced raters with the highest inter-rater reliability with NPEs (Fig. 4A) tended to be more reliable compared with using the H-B category scale (i.e., the difference between inter-rater reliabilities was greatest at high values of NPEs), while the less reliable inter-rater assessments tended to be closer to the H-B inter-rater reliability, or even less reliable (i.e.,

Table 9. Results of regression analysis comparing Lin's concordance correlation (LCC) variables (bias, accuracy, precision, and agreement) from all raters assessing scab severity on pecan fruit valves

\begin{tabular}{|c|c|c|c|c|c|c|}
\hline $\mathrm{LCC}^{\mathrm{a}}$ & Variable relationship tested ${ }^{b}$ & $F$ value $(P>F)^{\text {c }}$ & $a$ & $b$ & $R^{2 \mathrm{~d}}$ & $C V^{\mathrm{e}}$ \\
\hline \multirow[t]{3}{*}{$v$} & $\mathrm{NPE} \times \mathrm{H}-\mathrm{B}$ & $18.3(0.0005)$ & 0.63 & 0.42 & 0.50 & 7.2 \\
\hline & $\mathrm{NPE} \times \mathrm{NPEH}-\mathrm{B}$ & $192(<0.0001)$ & 0.19 & 0.84 & 0.91 & 3.0 \\
\hline & H-B $\times$ NPEH-B & $20.5(0.0003)$ & -0.02 & 1.07 & 0.53 & 11.3 \\
\hline \multirow[t]{3}{*}{$\mu$} & $\mathrm{NPE} \times \mathrm{H}-\mathrm{B}$ & $18.4(0.0004)$ & 0.06 & 0.65 & 0.51 & 121.8 \\
\hline & NPE $\times$ NPEH $-\mathrm{B}$ & $818(<0.0001)$ & 0.01 & 0.04 & 0.98 & 25.4 \\
\hline & H-B $\times$ NPEH-B & $18.0(0.0005)$ & 0.03 & 0.78 & 0.50 & 140.8 \\
\hline \multirow[t]{3}{*}{$\mathrm{C}_{\mathrm{b}}$} & $\mathrm{NPE} \times \mathrm{H}-\mathrm{B}$ & $17.6(0.0005)$ & 0.24 & 0.76 & 0.50 & 5.3 \\
\hline & NPE $\times$ NPEH $-\mathrm{B}$ & $819(<0.0001)$ & -0.10 & 1.10 & 0.98 & 1.1 \\
\hline & H-B $\times$ NPEH-B & $16.0(0.0008)$ & 0.27 & 0.70 & 0.47 & 5.0 \\
\hline \multirow[t]{3}{*}{$r$} & $\mathrm{NPE} \times \mathrm{H}-\mathrm{B}$ & $13.5(0.0017)$ & 0.21 & 0.78 & 0.43 & 6.2 \\
\hline & NPE $\times$ NPEH-B & $105(<0.0001)$ & 0.03 & 0.98 & 0.85 & 3.1 \\
\hline & H-B $\times$ NPEH-B & $7.1(0.02)$ & 0.48 & 0.47 & 0.28 & 5.9 \\
\hline \multirow[t]{3}{*}{$\rho_{\mathrm{c}}$} & $\mathrm{NPE} \times \mathrm{H}-\mathrm{B}$ & $19.2(0.0004)$ & 0.26 & 0.72 & 0.52 & 8.2 \\
\hline & NPE $\times$ NPEH-B & $185(<0.0001)$ & -0.01 & 1.02 & 0.91 & 3.5 \\
\hline & $\mathrm{H}-\mathrm{B} \times \mathrm{NPEH}-\mathrm{B}$ & $11.0(0.004)$ & 0.29 & 0.65 & 0.38 & 9.5 \\
\hline
\end{tabular}

${ }^{a}$ LCC variables: $v=$ scale bias, or slope shift $(1=$ no bias relative to the concordance line $) ; \mu=$ location bias, or height shift $(0=$ no bias relative to the concordance line); $\mathrm{C}_{\mathrm{b}}=$ correction factor, which measures how far the best-fit line deviates from $45^{\circ}$ and, thus, is a measure of accuracy; $r=$ correlation coefficient, which measures precision; and $\rho_{\mathrm{c}}=\mathrm{LCC}$ coefficient, which combines both measures of precision $(r)$ and accuracy $\left(\mathrm{C}_{\mathrm{b}}\right)$ to measure the degree of agreement with the true value.

${ }^{b}$ Disease severity estimated by nearest percent estimates (NPEs), the Horsfall-Barratt scale (H-B), or by conversion of the NPE to the Horsfall-Barratt midpoint (NPEH-B).

${ }^{\mathrm{c}} F$ value and probability indicates suitability of the linear regression model, where the regression function $y=a+b x$, and $a$ is the intercept and $b$ the slope parameter.

${ }^{\mathrm{d}}$ Coefficient of determination.

${ }^{\mathrm{e}}$ Coefficient of variation $(C V)$ is a unitless measure of variation, and is calculated as (mean square error/mean) $\times 100$.
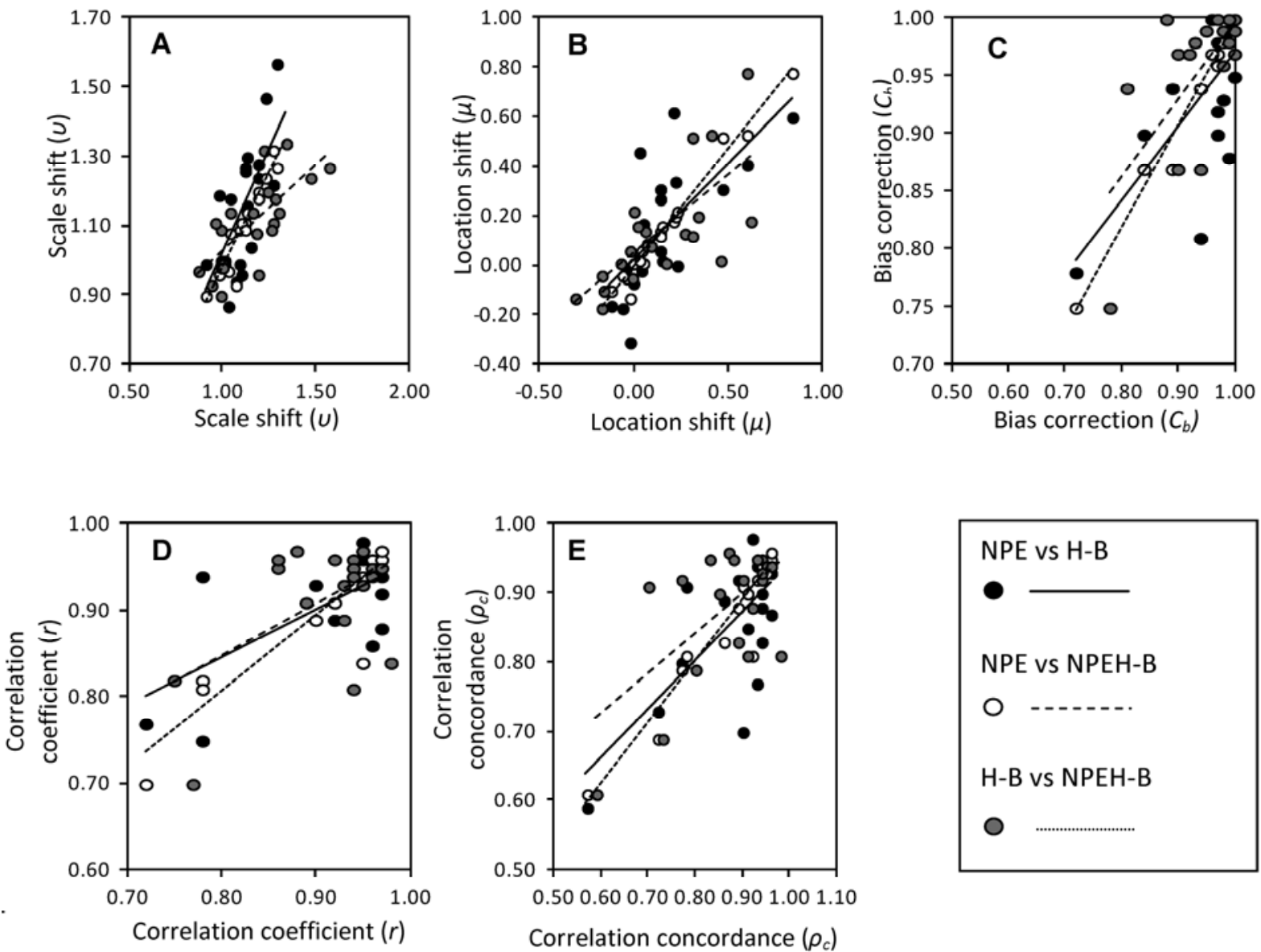

Fig. 2. Regression analysis comparing bias (A and B), accuracy (C), precision (D), and agreement (E) values for scab severity assessments on pecan fruit valves by estimating disease severity using either the nearest percent estimate (NPEs) method, the Horsfall-Barratt category scale (H-B), or conversion of the NPE method estimates to the Horsfall-Barratt mid-point (NPEH-B). Regression parameters are shown in Table 9. 
the difference between methods was less than 0). The same trend was seen for inexperienced raters (Fig. 4B), although they had a greater frequency of lower inter-rater reliabilities compared with experienced raters. The relationships were similar for the interrater reliabilities of the $\mathrm{H}-\mathrm{B}$ scale compared with the difference (H-B - NPEH-B) for both experienced (Fig. 4C) and inexperienced (Fig. 4D) raters. Comparing experienced inter-rater reliabilities of NPEs to the difference (NPE - NPEH-B) showed no relationship (Fig. 4E), with most inter-rater reliability differences close to zero. However, with inexperienced raters, there was a linear relationship implying that the better raters in this group tended to exhibit better inter-rater reliabilities using the NPE method compared with NPEH-B converted data (Fig.

Table 10. Inter-rater reliability of visual assessments by raters assessing scab severity on pecan fruit valves ${ }^{\mathrm{a}}$

\begin{tabular}{llccc}
\hline Cohort, rater & $\begin{array}{c}\text { Assessment } \\
\text { method }^{\mathbf{c}}\end{array}$ & $\begin{array}{c}\text { Intra-class } \\
\boldsymbol{\rho}^{\mathbf{d}}\end{array}$ & $\begin{array}{c}\text { Mean } \\
\boldsymbol{R}^{\mathbf{2}}\end{array}$ & $\begin{array}{c}\text { Mean inter- } \\
\text { rater } \boldsymbol{C V}^{\mathbf{f}}\end{array}$ \\
\hline Cohort 1 & & & & \\
Inexperienced & NPEs & 0.90 & 0.65 & 70.5 \\
& H-B & 0.87 & 0.60 & 90.8 \\
& NPEH-B & 0.89 & 0.59 & 78.9 \\
Experienced & NPEs & 0.97 & 0.86 & 36.1 \\
& H-B & 0.95 & 0.84 & 41.3 \\
Cohort 2 & NPEH-B & 0.93 & 0.81 & 41.5 \\
Inexperienced & NPEs & 0.94 & 0.85 & 42.8 \\
& H-B & 0.94 & 0.78 & 54.7 \\
Experienced & NPEH-B & 0.96 & 0.68 & 63.4 \\
& NPEs & 0.97 & 0.96 & 24.1 \\
& H-B & 0.94 & 0.77 & 52.6 \\
& NPEH-B & 0.95 & 0.92 & 31.5 \\
\hline
\end{tabular}

a Inter-rater reliability was measured by the intra-class correlation coefficient $(\rho)$ and coefficient of determination $\left(R^{2}\right)$.

${ }^{\mathrm{b}}$ Image cohort and rater experience. Raters assessed two sets of 40 images (cohorts 1 and 2).

c Disease severity was estimated by nearest percent estimates (NPEs), the Horsfall-Barratt scale (H-B), or by conversion of the NPE to the HorsfallBarratt mid-point (NPEH-B).

${ }^{d}$ Intra-class correlation coefficient $(\rho)$.

${ }^{\mathrm{e}}$ Mean inter-rater coefficients of determination $\left(R^{2}\right)$ estimated from pairwise comparisons of assessments by all visual assessors.

${ }^{\mathrm{f}}$ Coefficient of variation $(\mathrm{CV})$ is a unitless measure of variation, and is calculated as (mean square error/mean) $\times 100$.

Table 11. Bootstrap analysis of the difference between the means of interrater reliability (coefficient of determination $\left[R^{2}\right]$ ) of visual assessments of scab severity on images of pecan fruit valves ${ }^{\mathrm{a}}$

\begin{tabular}{|c|c|c|c|}
\hline Rater, cohort ${ }^{\text {b }}$ & $\begin{array}{c}\text { Variable } \\
\text { relationship tested }^{\mathrm{c}}\end{array}$ & Mean diff ${ }^{d}$ & $95 \% \mathrm{CIs}^{\mathrm{e}}$ \\
\hline \multicolumn{4}{|l|}{ Inexperienced } \\
\hline \multirow[t]{3}{*}{ Cohort 1} & $\mathrm{NPE} \times \mathrm{H}-\mathrm{B}$ & -0.044 & $-0.118-0.023$ \\
\hline & NPE $\times$ NPEH-B & -0.060 & $-0.113--0.008$ \\
\hline & H-B $\times$ NPEH-B & 0.017 & $-0.057-0.098$ \\
\hline \multirow[t]{3}{*}{ Cohort 2} & $\mathrm{NPE} \times \mathrm{H}-\mathrm{B}$ & -0.246 & $-0.320--0.169$ \\
\hline & NPE $\times$ NPEH-B & -0.169 & $-0.228--0.110$ \\
\hline & $\mathrm{H}-\mathrm{B} \times \mathrm{NPEH}-\mathrm{B}$ & 0.098 & $-0.016-0.196$ \\
\hline \multicolumn{4}{|l|}{ Experienced } \\
\hline \multirow[t]{3}{*}{ Cohort 1} & $\mathrm{NPE} \times \mathrm{H}-\mathrm{B}$ & -0.023 & $-0.052-0.008$ \\
\hline & $\mathrm{NPE} \times \mathrm{NPEH}-\mathrm{B}$ & -0.046 & $-0.065--0.023$ \\
\hline & $\mathrm{H}-\mathrm{B} \times \mathrm{NPEH}-\mathrm{B}$ & 0.021 & $-0.006-0.049$ \\
\hline \multirow{3}{*}{ Cohort 2} & $\mathrm{NPE} \times \mathrm{H}-\mathrm{B}$ & -0.120 & $-0.162--0.088$ \\
\hline & NPE $\times$ NPEH-B & -0.032 & $-0.042--0.022$ \\
\hline & $\mathrm{H}-\mathrm{B} \times \mathrm{NPEH}-\mathrm{B}$ & -0.155 & $-0.232--0.086$ \\
\hline
\end{tabular}

a Bold text indicates a significant difference.

${ }^{\mathrm{b}}$ Rater experience and image cohort. Raters assessed two sets of 40 images (cohorts 1 and 2).

${ }^{c}$ Disease severity was estimated by nearest percent estimates (NPEs), the Horsfall-Barratt scale (H-B), or by conversion of the NPE to the HorsfallBarratt mid-point (NPEH-B).

${ }^{\mathrm{d}}$ Mean of the difference between each rating.

${ }^{\mathrm{e}}$ Confidence intervals (CIs) were based on 2,000 bootstrap samples. If the CIs embrace zero, the difference is not significant $(\alpha=0.05)$.
4F) but, at lower NPE inter-rater reliabilities, the two methods were equivalent.

Time and assessment method. Although the bootstrap analysis indicated no difference in absolute time needed to assess disease severity, regression analysis of the relationship between time needed to assess images using the NPE assessment method and the difference in time to perform the assessments using the NPE or H$\mathrm{B}$ category scale methods (time to assess with NPEs - time to assess with the H-B scale) suggests that raters who are inherently fast when assessing disease severity using the NPE method are slower using the H-B category scale method (Fig. 5). However, those raters who are slow in assessing disease severity using the NPE method are often faster using the H-B category scale.

\section{Discussion}

The H-B category scale did not improve the accuracy or precision of disease severity estimates of pecan scab by either inexperienced or experienced raters. The finding that category scales did not improve the accuracy or precision of disease severity estimates agrees with results of other studies $(1,4,11,19)$. In fact, some studies demonstrated that, in some cases, logarithmic category scales are inferior to the NPE method $(1,5)$ and, in the current study, some of the measurement statistics showed that the H-B scale (or conversion to the H-B scale) could result in less accurate or precise data compared with the NPE method. However, for most measures of accuracy, precision, or agreement, the two methods were not significantly different and provided no evidence that there is a benefit to rating pecan scab using a logarithmic category scale (15).

There was not much difference in accuracy, precision, or agreement between inexperienced or experienced raters using the NPE method, the H-B category scale, or the data based on the NPEH-B conversion. Previous studies comparing rater experience have most often found significant differences between these two groups $(1,7,19,23,29)$. One reason for the lack of an apparent difference between experienced and inexperienced raters in the current study might be due to the fact that most of the raters classed as "inexperienced" had bias, accuracy, precision, and agreement values that were very similar to the experienced group (thus, they were inherently accurate and precise), although there were exceptions; for example, rater 1 was imprecise and inaccurate, and consistently overestimated disease severity. Raters are known to vary in ability, and the brief instruction given at the beginning of each assessment combined with an inherently good ability presumably meant that

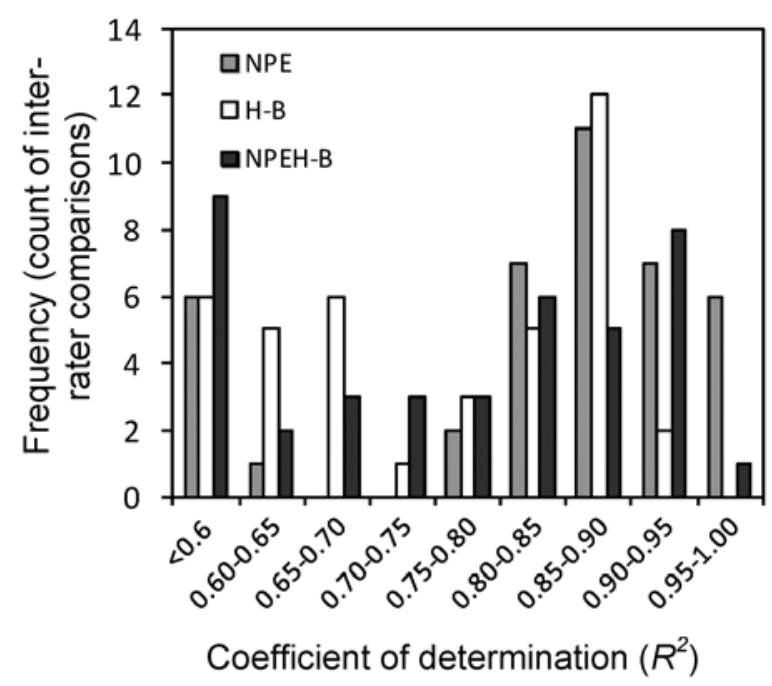

Fig. 3. Frequency of the inter-rater reliability measured by the coefficient of determination $\left(R^{2}\right)$ obtained by raters assessing scab severity on pecan fruit valves by the nearest percent estimate (NPEs) method, the Horsfall-Barratt category scale (H-B), or converting the NPE method estimates to the Horsfall-Barratt mid-point (NPEH-B). 
most of the inexperienced raters had scores similar to the experienced group (1).

Some previous studies comparing category scales have relied on converting the NPEs to the category scale (most often the H-B scale; 4,19), with the assumption that converting an NPE is equivalent to how a rater would assign an NPE to the most appropriate category. The risk with doing this is that, when raters actually apply the H-B scale directly to assess disease, the results may be different (11). Thus, we compared the assessments using the $\mathrm{H}-\mathrm{B}$ scale with the data from the NPEH-B conversion. The results of the bootstrap analyses comparing methods and the regression analysis both indicated that, in this study, there were relatively minor effects of specific assessment methods on accuracy, precision, or agreement, and the proportion of incorrectly assigned categories (and those that were over- or underestimates) appeared to be similar whether direct H-B assessments were made or the NPEs were converted to H-B midpoint values. These results support the previous studies that have used a conversion to simulate H-B assessment.

One facet of scales that has not been explored previously is the effect on the sample mean. These data demonstrated that, for some raters' assessments, using the H-B scale can have a profound effect on the estimate of the mean, with it being $>10 \%$ different compared with the estimates obtained using the NPE method and the actual value. This effect was only noticed using the direct $\mathrm{H}-\mathrm{B}$ estimates and not the converted NPEH-B data, which was used in previous studies $(4,19)$. Thus, in most cases, converting NPE method estimates to the H-B category scale had little effect on the mean, although there may be situations when it does not mimic the ability of a rater assessing disease. In a few cases, it might also
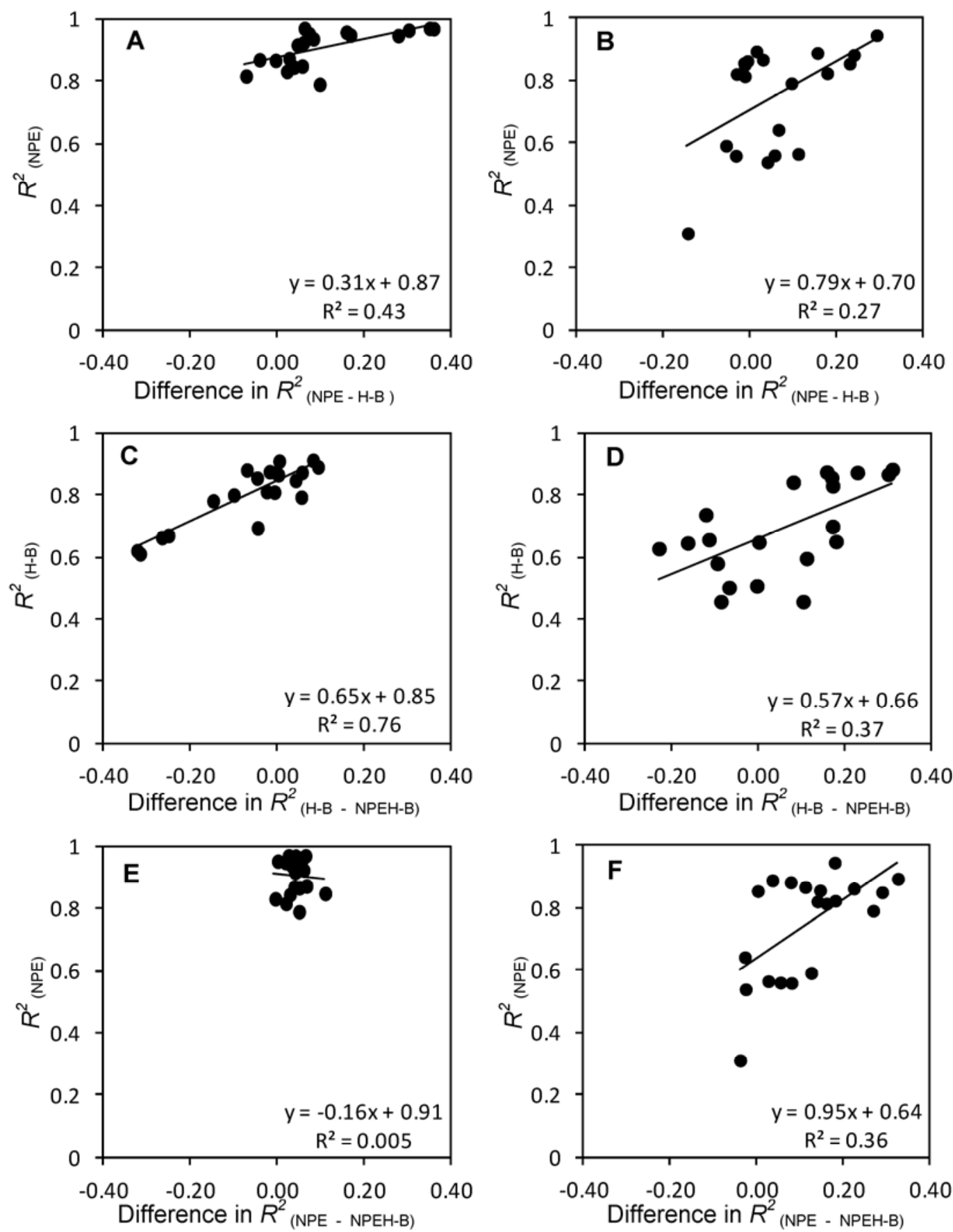

Fig. 4. Difference between inter-rater reliability measures and $\left(R^{2}\right)$ and the inter-rater reliability values for each method for $\mathbf{A}, \mathbf{C}$, and $\mathbf{E}$, experienced and $\mathbf{B}$, D, and $\mathbf{F}$, inexperienced raters assessing scab severity on pecan fruit valves either by estimating disease severity by nearest percent estimates (NPEs), the Horsfall-Barratt scale (HB), or conversion of the NPE to the Horsfall-Barratt mid-point (NPEH-B). 
affect treatment means comparisons that are based on $\mathrm{H}-\mathrm{B}$ scale data (5).

Inter-rater reliability among the three methods confirmed previous observations that the H-B category scale reduces reliability $(1,4,19)$, with both direct H-B assessments and the converted NPEH-B significantly reducing reliability compared with NPEs. Significant differences in reliability when comparing the NPE and NPEH-B data for both experienced and inexperienced raters indicated that NPEs were preferable when assessing disease with multiple raters.

There is a perception that the H-B category scale (or other logarithmic category scales) is faster to use than the NPE method. Our data did not bear this out. Bootstrap analysis indicated no significant difference for inexperienced or experienced raters assessing pecan scab severity using either the H-B category scale or the NPE method. However, although there was no direct difference, there was still a discernible response in the difference in duration of assessment to assessment method used by raters. The results suggested that those raters who were inherently rapid in assessing disease severity using the NPE method will most often be slower when assessing using the H-B category scale. However, raters who are slow using the NPE method will most often be faster if assessing using the H-B category scale. Raters (not necessarily experienced or inexperienced) might agonize over the correct classification category in a category scale more than when allocating an NPE. The slight saving in time with slow raters would only be advantageous if their estimates provided good agreement with actual values, and if they exhibited high inter-rater reliability.

There might be some situations where a category scale is still useful (for example, rating germplasm) but, where accurate, precise, and reliable disease assessment data is required, the NPE method was invariably as good as and sometimes better than using a logarithmic category scale. If a scale is to be used, it would benefit the data to have a linear structure (19) because not only has the basis for the logarithmic-type H-B scale been shown to be incorrect $(7,20,21)$ but it also is possible to estimate disease severity more accurately using a linear 0 -to-100 scale than using the midgrades of a log-based category scale $(5,20)$. Forbes and Korva (11) provide compelling reasons not to use $\mathrm{H}-\mathrm{B}$ type category scales. A nonlinear scale like the $\mathrm{H}-\mathrm{B}$ scale offers no obvious advantages to assessing the severity of pecan scab, and certainly does not improve the quality of the assessment, and it is doubtful that it offers useful advantages in time saved.

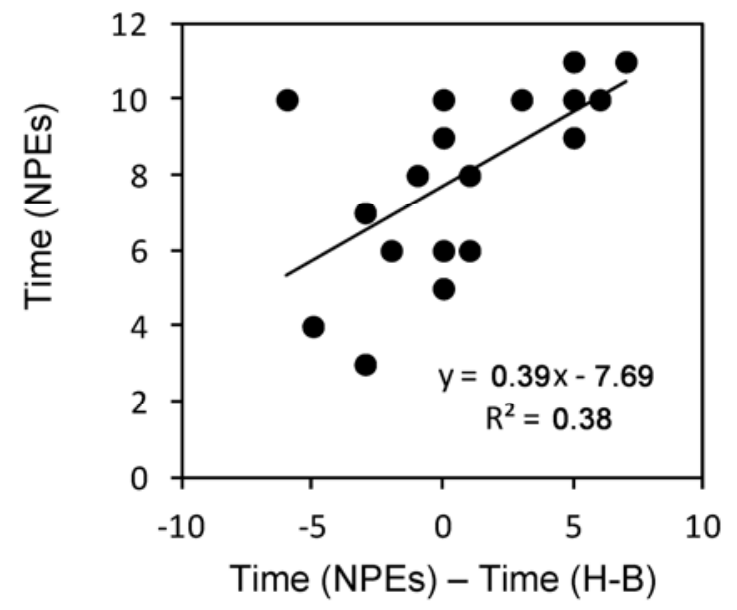

Fig. 5. Relationship between time taken to assess severity of pecan scab on two sets of 40 images of diseased pecan valves using nearest percent estimates (NPEs) or the Horsfall-Barratt (H-B) scale and the difference between the time taken by NPEs minus time taken by the H-B scale (NPEs - H-B), showing a tendency for raters who were faster assessing by NPEs to be slower using the H-B scale, whereas raters who were slow using NPEs tended to be relatively faster using the $\mathrm{H}-\mathrm{B}$ scale.

\section{Acknowledgments}

We thank students from the Morehouse University Upward Bound program and from colleagues at the USDA-ARS-SEFTNRL for taking the time to assess the disease images.

\section{Literature Cited}

1. Bardsley, S. J., and Ngugi, H. K. Reliability and accuracy of visual methods used to quantify severity of foliar bacterial spot symptoms on peach and nectarine. Plant Pathol. In press.

2. Bertrand, P. F., Brenneman, T. B., and Stevenson, K. C. 1999., Disease assessment and uniformity in rating methods. Pages 124 to 128 in: Pecan Industry: Current Situation and Future Challenges, Third National Pecan Workshop Proceedings. B. McGraw, E. H. Dean, and B. W. Wood, eds. U.S. Dep. Agric.-Agric. Res. Serv., 1998-04.

3. Bock, C. H., Brenneman, T. B., Hotchkiss, M. W., and Wood, B. W. 2012. Evaluation of a phosphite fungicide to control pecan scab in the southeastern USA. Crop Prot. 36:58-64.

4. Bock, C. H., Gottwald, T. R., Parker, P. E., Cook, A. Z., Ferrandino, F., Parnell, S., and van den Bosch, F. 2009. The Horsfall-Barratt scale and severity estimates of citrus canker. Eur. J. Plant Pathol. 125:23-38.

5. Bock, C. H., Gottwald, T. R., Parker, P. E., Ferrandino, F., Welham, S., van den Bosch, F., and Parnell, S. 2010. Some consequences of using the Horsfall-Barratt scale for hypothesis testing. Phytopathology 100:1031-1041.

6. Bock, C. H., Parker, P. E., Cook, A. Z., and Gottwald, T. R. 2008. Visual rating and the use of image analysis for assessing different symptoms of citrus canker on grapefruit leaves. Plant Dis. 92:530-541.

7. Bock, C. H., Parker, P. E., Cook, A. Z., Riley, T., and, Gottwald, T. R. 2009. Comparison of assessment of citrus canker foliar symptoms by experienced and inexperienced raters. Plant Dis. 93:412-424.

8. Bock, C. H., Poole, G., Parker, P. E., and Gottwald, T. R. 2010. Plant disease severity estimated visually, by digital photography and image analysis, and by hyperspectral imaging. Crit. Rev. Plant Sci. 29:59-107.

9. Campbell, C. L., and Madden, L. V. 1990. Introduction to Plant Disease Epidemiology. J. Wiley \& Sons, New York.

10. Everitt, B. S. 1998. The Cambridge Dictionary of Statistics. Cambridge University Press, Cambridge.

11. Forbes, G. A., and Korva, J. T. 1994. The effect of using a Horsfall-Barratt scale on precision and accuracy of visual estimation of potato late blight severity in the field. Plant Pathol. 43:675-682.

12. Gottwald, T. R., and Bertrand, P. F. 1983. Effect of time of inoculation with Cladosporium caryigenum on pecan scab development and nut quality. Phytopathology 73:714-718.

13. Herbert, T. T. 1982. The rationale for the Horsfall-Barratt plant disease assessment scale. Phytopathology 72:1269.

14. Horsfall, J. G., and Barratt, R. W. 1945. An improved grading system for measuring plant disease. (Abstr.) Phytopathology 35:655.

15. Hunter, R. E., and Roberts, D. D. 1978. A disease grading system for pecan scab. Pecan Q. 12:3-6.

16. Lamari, L. 2002. ASSESS: Image Analysis Software for Plant Disease Quantification. American Phytopathological Society, St. Paul, MN.

17. Lin, L. I. 1989. A concordance correlation coefficient to evaluate reproducibility. Biometrics 45:255-268.

18. Madden, L. V., Hughes, G., and van den Bosch, F. 2007. The Study of Plant Disease Epidemics. American Phytopathological Society, St. Paul, MN.

19. Nita, M., Ellis, M. A., and Madden, L. V. 2003. Reliability and accuracy of visual estimation of Phomopsis leaf blight of strawberry. Phytopathology 93:995-1005.

20. Nutter, F. W., Jr., and Esker, P. D. 2006. The role of psychophysics in phytopathology. Eur. J. Plant Pathol. 114:199-213.

21. Nutter, F. W., Jr., and Schultz, P. M. 1995. Improving the accuracy and precision of disease assessments: selection of methods and use of computeraided training programs. Can. J. Plant Pathol. 17:174-185.

22. Nutter, F. W., Jr., Teng, P. S., and Shokes, F. M. 1991. Disease assessment terms and concepts. Plant Dis. 75:1187-1188.

23. Parker, S. R., Shaw, M. W., and Royle, D. J. 1995. Reliable measurement of disease severity. Asp. Appl. Biol. 43:205-214.

24. Redman, C. E., King, E. P., and Brown, I. F., Jr. 1969. Tables for Converting Barratt and Horsfall Rating Scores to Estimated Mean Percentages. Elanco Products, Indianapolis, IN.

25. Slopek, S. W. 1989. An improved method for estimating percent leaf area diseased using a 1 to 5 disease assessment scale. Can. J. Plant Pathol. 11:381-387.

26. Stevenson, K. L., and Bertrand, P. F. 2001. Within-season dynamics of yield loss due to pecan scab fruit infections. (Abstr.) Phytopathology 91:S85.

27. Wood, B. W. 2001. Production unit trends and price characteristics within the United States pecan industry. HortTechnology 11:110-118.

28. Wood, B. W. 2003. Pecan production in North America. Southwest. Ent. (Suppl. 27):1-19.

29. Yadav, N. V. S., de Vos, S. M., Bock, C. H., and Wood, B. W. Development and validation of standard area diagrams to aide assessment of pecan scab symptoms on pecan fruit. Plant Pathol. In press.

30. Yi, Q., Wang, P. P., and He, Y. 2008. Reliability analysis for continuous measurements: Equivalence test for agreement. Stat. Med. 27:2816-2825. 